\title{
Effects of M edia Use Behavior on the Channel Bundle Preferences
}

\author{
JooHyeon Kim* and Sangin Park**
}

\begin{abstract}
This paper analyzes the factors that influence what kinds of preferences consumers display with respect to channel bundles provided by multichannel services (cable TV, DBS and IPTV) in Korea, focusing on consumers' media use behaviors as key determinants. For the analysis, we use the mixed logit model and estimate the coefficients of interaction terms between household attributes and characteristics of the channel bundles offered by multichannel services. We find that households that prefer channel bundles composed of higher viewer-rating programs have a tendency to spend more time watching terrestrial broadcaster's programs than other TV programs and allocate more time for surfing the internet; that households that prefer channel bundles featuring various genres are likely to spend more time surfing the internet and watching VOD via TV or other digital devices; and that single dwellers or married couples without children have preferences for channel bundles composed of more watched channels, while upper-income households are less sensitive to price.
\end{abstract}

Keywords: multichannel services, channel bundle, media use behavior, mixed logit model

\section{INTRODUCTION}

Media use patterns have changed greatly with the arrival of the era of digital convergence; smart devices make media content accessible anywhere and at any time. In particular, the way of watching video content has been diversified as new platforms and internet-based services have emerged.

Digital convergence also affects the structure of the multichannel services market. Multichannel services in Korea are provided by 91 local cable system operators (SO),

\footnotetext{
* JooHyeon Kim is a PhD student in the Graduate School of Public Administration, Seoul National University. E-mail: pipi007@snu.ac.kr.

** Sangin Park, the corresponding author, is a professor in Graduate School of Public Administration, Seoul National University. E-mail: sanpark@snu.ac.kr.
}

Manuscript received February 13, 2016; out for review March 1, 2016; review completed March 21, 2016; accepted March 24, 2016.

The Korean Journal of Policy Studies, Vol. 31, No. 1 (2016), pp. 113-131.

(C) 2016 by the GSPA, Seoul National University 
one direct-broadcast satellite (DBS) provider, KT-Skylife, and three internet protocol TV (IPTV) providers, SK Broadband, KT, and LG U plus. According to the Broadcasting Industry Survey conducted by the Korea Communications Commission (KCC), the number of subscribers to multichannel services was 26,565,511 (port) at the end of June 2013, which reflected a $36.79 \%$ increase since June 2009. The number of subscribers to digital cable TV has been on the rise, and the market share of MSOs (multiple system operators) has increased as well, while analog cable TV service decreased from 2009 to $2013 .^{1}$ The number of households that subscribed to digital cable TV increased by about 2.5 times from 2009 to 2013 to 5,701,385 (21.46\% of all multichannel service subscribers). Meanwhile, the number of analog cable TV subscribers decreased from $12,806,753$ to $9,141,980$ during same period, and the industry experienced a sharp decline of market share from $65.94 \%$ to $34.41 \%$. DBS subscribers were $4,006,850$ and accounted for $15.08 \%$ of all multichannel service subscribers in 2013 , increasing by roughly 1.69 times from 2009. IPTV services, launched in January 2009, have been growing rapidly. The number of IPTV subscribers accounted for $28.60 \%$ of all multichannel service subscribers at the end of June 2013, reaching $7,596,524,4.5$ times higher than that of 2009. These data show that platforms for multichannel services have been diversified with the rise of digital cable and IPTV and that multichannel service providers have been facing accelerating competition from the entry of new companies.

Even though competition is intense among multichannel service providers, channel bundles are offered at similar prices if they are in the same tier, which is tied to the number of channels provided in the bundle. According to the Broadcast Act in Korea, cable SOs and DBS provider are required to obtain the approval of the government for the ceiling of price they propose to charge for their channel bundles. IPTV service prices are also regulated by the government in accordance with the Internet-Multimedia Broadcast Act. In addition, multichannel service providers have to provide must-carry channels designated by the government.

Viewers, however, have more ways to consume video content than ever before. There are more alternatives to multichannel services from which to choose. In addition, consumption of on-demand content distributed over the internet has proliferated, and consumers are seeking more diverse content. Therefore, it is possible that multichannel service providers will try to develop new competitive strategies that are in line the current governmental regulations in order to catch up with consumers' new media use

1. MSOs operate in more than two regions. In 2013, 5 MSOs operated in 81 regions out of the total 92 regions in Korea, and their share was 88.6\% of the cable TV market (Korea Communications Commission, 2013). 
behavior, tailoring channel contents and services to them.

Our paper empirically analyzes the correlations between consumer attributes and the characteristics of multichannel services, focusing on consumers' media use behavior. Several papers have addressed factors that influence what kind of multichannel service consumers chose (Bok, 2012; Goolsbee \& Petrin, 2004; Wise \& Duwadi, 2005; Yoon, Lee, \& Lee, 2006). But they do not fully take into account the effect of the changes in media use on multichannel service consumption. In this paper, we combine householdlevel data, including media use behavior, with multichannel service data to estimate the coefficients of interaction terms between household attributes and the characteristics of multichannel services. For this estimation, we use the mixed logit model.

The paper proceeds as follows. In section 2, we explore previous research on changes in media use and factors influencing consumption of multichannel services. In section 3, we describe our estimation model, data, and variables. In section 4, we provide the estimation results and discuss the implications of these results. In section 5 , we provide our conclusion.

\section{LITERATURE REVIEW}

\section{Changes in Media Use}

Studies of changes in media use have mainly focused on whether emerging new media has replaced traditional media or instead complements it. Media substitution theory suggests that because people have a limited amount of time to utilize media, when new media is introduced and perceived as more desirable than traditional forms, people will accept it and establish new media use behaviors (Han \& Lee, 2012; Kaye \& Johnson, 2003). But according to media complementarity theory, new and traditional media may coexist in a complementary relationship, and each may separately evolve based on their unique features (Han \& Lee, 2012).

Empirical studies have not revealed a coherent pattern of either media substitution or complementarity. Some researchers suggest that internet usage reduces the time spent watching TV (Kang, 2000; Lee, 2013; Hwang, 2004; Perguson \& Perse, 2000; James, Wotring, \& Forrest, 1995), while others have argued that the increase of internet usage extends the time spent watching TV (Lee, 2009) or there is a positive correlation between the degrees of people's dependence on TV and the internet (Yu, 2004).

Several studies addressed the effect of smartphone usage on the other media use. Lee \& $\mathrm{Na}$ (2012) argue that the use of smartphone applications has reduced the use of MP3 player, radio, and newspaper by approximately 50\%, while it rarely affects the 
time spent using a personal computer or TV. Kim, Kim \& Jeong (2013) find that smartphone use is correlated with the use of the internet, newspapers, and game media, but that it did not reduce the use of TV or radio at a statistically significant level. Similarly, Lim, Yoon \& Jo (2013) show that the use of mobile media does not reduce the amount of time spent watching TV. Lee \& Lee (2013) examine the effect of watching online VOD on the time allocation for other daily activities and found that as the amount of time spent watching online VOD increases, time spent watching cableTV or playing games decreases. They also argue that this tendency to substitute online VOD for other media increases as time goes by.

Here we direct attention to how consumers' media use behavior affects their TV channel bundle preferences. Since the channel bundle is not fixed and will evolve as consumers' media use changes in the course of digital convergence, our paper is a first step toward understanding the dynamics between media use and content offerings in traditional and new media.

\section{Factors Influencing the Consumption of Multichannel Services}

Several researchers have examined the competition among multichannel services, uncovering factors influencing consumers' choices. Goolsbee \& Petrin (2004) estimate a consumer-level demand system for DBS, basic cable tier, premium cable tier, and local antenna, examining the response of cable SOs to entry of DBS. They show that single men and single-unit dwellers are more likely to adopt DBS than multiunit dwellers, and that non-renters are more likely to subscribe to DBS. In addition, household income has positive effects on the DBS adoption, whereas households with members who have a high education level are less likely to subscribe to DBS. Wise \& Duwadi (2005) argue that the cost of switching from cable TV to DBS as well as regional sports channels of local cable TV plays a key role in the consumer's decision to switch from cable TV to DBS.

Bok (2012) estimates the conversion rate of multichannel service consumption by using the mixed logit model. He suggests demographics such as the age and education level of household, the size of household, type of dwelling (single- or multi-unit dwelling) have statistically significant correlations with characteristics of multichannel services such as the number of available channels, the number of channels weighed by viewer ratings, the degree of genre diversity, and the availability of VOD service.

As the multichannel service market expands along with the number of channels offered, some studies have focused on the relation between patterns of viewers' content consumption and the multichannel services they choose to subscribe to. Yoon et al. (2006) argue that people who spend more hours watching TV and who gravitate 
toward terrestrial TV channels are less likely to subscribe to DBS. Similarly, Park \& Jung (2010) suggest that if the household spends less time watching terrestrial TV channels or has more experience of switching among multichannel services, it is more likely to subscribe to IPTV. Jo \& Kang (2008) show that although the number of channels provided by multichannel services has proliferated, viewers' channel repertoire has not changed a lot and still mainly consists of terrestrial TV channels. However, Park (2009) argues that IPTV subscribers strongly prefer the channels provided by CJ and On-media, the major (non-terrestrial TV channel) program providers in Korea.

These studies fall short of discussing the relationship between consumers' use of new media and their household's subscription to multichannel services. There is a high possibility that consumers' new media usage pattern in the wake of digital convergence affects their preference for specific characteristics of multichannel services and hence their choices of services.

\section{RESEARCH METHOD}

\section{Mixed Logit Model}

We adopt the mixed logit model and estimate the coefficients of interaction terms between consumers' attributes and the characteristics of channel bundles to analyze the consumption of multichannel services. ${ }^{2}$ We define consumer $i$ 's utility function for alternative (multichannel service) $j$ as follows:

$$
U_{i j}=\delta_{j}+\sum_{k} \sum_{r=1}^{R} x_{j k} z_{i r} r_{k r}+d_{j} v_{i} r^{u}+\varepsilon_{i j}
$$

$\delta_{j}$ is the mean utility level from choosing alternative $j$, while the other terms on the right- hand side of the equation indicate individual $i$ 's utility received by choosing alternative $j$. The second term represents interactions between the observed attribute of the consumer and the observed characteristic of the alternative, where $x_{j k}$ is the $k_{t h}$ observable characteristic of multichannel service $j, z_{i r}$ is consumer i's observable attribute, and $r_{k r}$ represents the coefficient of the interaction term. The third term indicates that consumer $i$ 's unobservable attribute $\left(v_{i}\right)$ affects her utility level of alternative $j$, where $d_{j}$ is a dummy variable for alternative $j$ and $r^{u}$ is the coefficient of the term. In the mixed logit model, it is assumed that $v_{i}$ is IID (independent and identically

2. For more details on mixed logit model, refer to Park (2010). 
distributed) by following the standard normal distribution. Lastly, $\varepsilon_{i j}$ denotes consumer $i$ 's idiosyncratic tastes for alternative $j$, and it is IID by following the type I extreme value distribution.

Under the additional assumption that $v_{i}$ and $\varepsilon_{i j}$ are stochastically independent, the conditional probability that consumer $i$ selects alternative $j$ can be calculated as follows:

$$
P_{r}\left(y_{i}=j \mid x, \xi, z_{i}\right)=\int_{v} \frac{\exp \left(\delta_{j}+\sum_{k} \sum_{r=1}^{R} x_{j k} z_{i r} r_{k r}+d_{j} v_{i} r^{u}\right.}{1+\sum_{d} \exp \left(\delta_{d}+\sum_{k} \sum_{r=1}^{R} x_{d k} z_{i r} r_{k r}+d_{d} v_{i} r^{u}\right)} P_{0}\left(d_{v}\right)
$$

In equation $2, y_{i}=j$ indicates that consumer $i$ selects alternative $j$, and $P_{o}(d v)$ is the probability distribution function of $v=\left(v_{1}, \ldots, v_{n}\right)^{\prime}$, where $\mathrm{n}$ is the number of consumers.

Given that our purpose is to examine the interactions between the individual's attributes and the characteristics of multichannel services, we conduct a simulated maximum likelihood estimation to obtain the estimates of these interaction terms as well as $\delta_{j} \cdot 3$

\section{The Data}

We use the Korean Media Panel Survey conducted by Korean Information Society Development Institute in June-July 2013 to obtain household-level data on demographics, media use behavior, multichannel service subscription information, and the fees that each household paid for the multichannel service in the previous month.

The Korean Media Panel Survey has been conducted annually since 2010 in order to build a panel dataset on behavior of the households and individuals in the media environment of Korea. Individuals and households on the panel are asked to answer a questionnaire on demographics, the number and kind of media devices owned, media device connectivity, media use patterns, multichannel service subscription and expenditure, and so forth, and to keep a media dairy for three days.

4,381 households responded to the Korean Media Panel Survey in 2013. But we excluded four households from the data set that did not provide information such as the age of householder or the fees paid for analog cable TV. In addition, 78 households that subscribed to more than two services at the same time were dropped from the dataset.

The data on characteristics of multichannel services were collected from the multi-

3. After making this estimation, we can then estimate the coefficient of observable characteristics in the mean utility level of alternative $\mathrm{j}$ by conducting a regression analysis that uses the unobservable characteristics of alternative $j$ as an error term of the equation. 
channel service providers' homepages in July 2014. The data include price information for channel bundles, and the name and the TV number of each individual channel. The viewer ratings of channels from July 20 to August 9, 2014, were provided by Nielsen Korea.

Each multichannel service provider offers several channel bundles that are classified into tiers according to the price range. The Korean Media Panel Survey, however, does not provide information on the household's choice of tiers. However, based on the monthly fees that the household paid for the multichannel service in the previous month, we were able figure out the tier to which it subscribes in the case of households subscribing to analog cable packages (which amounts to about $50 \%$ of the entire households in the Korean Media Panel Survey). Unlike subscribers to analog cable packages, however, who do not typically have access to pay-per-view services and who are seldom offered discounts, subscribers to digital cable TV, DBS and IPTV can use VOD service and can secure discounts in many ways, which means that assigning a tier classification based on the fees charged for a given month was not possible for them. ${ }^{4}$

Analog cable TV services can be divided into three tiers. Tier 1, a package mainly composed of most watched channels, costs $\$ 4,000$ or less per month. Tier 2 ranges from $\mathbb{W}, 000$ to $\mathbb{W} 10,000$ per month. Tier 3 , a package including almost every channel

Table 1. Households' Channel Bundle Choices

\begin{tabular}{c|l|r|r}
\hline \multicolumn{2}{|c|}{ Options } & Number & Proportion (\%) \\
\hline 1 & No subscription & 346 & 8.23 \\
\hline 2 & analog cable TV tier 1 & 252 & 6.00 \\
\hline 3 & analog cable TV tier 2 & 1,623 & 38.62 \\
\hline 4 & analog cable TV tier 3 & 195 & 4.64 \\
\hline 5 & digital cable TV & 920 & 21.89 \\
\hline 6 & DBS & 211 & 5.02 \\
\hline 7 & IPTV & 656 & 15.61 \\
\hline
\end{tabular}

4. Multichannel service providers offer discounts when the consumer signs a 3-or 5-year contract or purchases a bundled service that combines TV service with other services for internet connection and mobile phone service. Only 96 households that subscribed to the analog cable TV package responded that they used bundled products in the 2013 Korean Media Panel Survey. These households were excluded from our data set. 
supplied by the service operator, ranges between $W 10,000$ and $W 15,000$ per month. In our data, we found that 34 households answered that they subscribed to an analog cable TV package, but they also said that they paid more than $\$ 18,000$ for the service per month. We have assumed that these 34 households were in fact digital cable TV subscribers, since the price ceiling of analog cable TV packages is $\mathbb{W} 15,000$, and the digital cable TV packages start from $¥ 18,000$.

Hence, we have 7 possible options for multichannel services, such as analog cable TV tier 1, analog cable TV tier 2, analog cable TV tier 3, a digital cable TV package, a DBS package, IPTV service, and 'no subscription' as an outside alternative. Table 1 provides the number of households that chose each option.

\section{Measurement of Variables}

The characteristics of multichannel services in this paper include genre diversity, average viewer rating, and the monthly fee for the channel bundle. First of all, we measured the degree of genre diversity for channel bundle $j$ by using $\operatorname{Simpson's~} D_{z}(j)$ index as follows:

$$
\text { Simpson's } D_{z}(j)=\frac{1-\sum_{i=1}^{k} p_{i j}^{2}}{1-\frac{1}{k}}
$$

$p_{i j}$ indicates the share of genre $i$ in channel bundle $j$, where $k$ means the total number of channel genres. ${ }^{5}$ We categorize the various channels into 21 genres, drawing on Broadcasting Industry Survey 2013.

The average viewer rating of channel bundle $j$ is defined as below:

$$
\text { average viewer } \operatorname{rating}(j)=\frac{1}{\mathrm{~L}} \sum_{i=1}^{L} w_{i} I_{i j}
$$

In equation $4, L$ is the number of all the channels available, and $w_{i}$ indicates the viewer rating of channel $i$, and $I_{i j}$ is a dummy variable that indicates whether channel bundle $j$ offers channel $i$. Table 3 shows the top 20 channels according to viewer ratings from July 20 to August 9, 2014.

5. We did not include terrestrial channels such as KBS1, KBS2, MBC, SBS, or EBS because these channels are carried by all channel bundles. 
Table 2. Classification of Channel Genres

\begin{tabular}{|c|c|c|}
\hline & Genre & Main Programming \\
\hline 1 & shopping & shopping \\
\hline 2 & news & news \\
\hline 3 & comprehensive programming channel & news, variety, drama, documentary, etc. \\
\hline 4 & public information & government(general/local), parliament, army \\
\hline 5 & specific audience & programs for seniors, the handicapped \\
\hline 6 & business \& finance & economy, stock market, real estate, finance \\
\hline 7 & documentaries \& culture & documentaries, nature, culture, arts \\
\hline 8 & education & education \\
\hline 9 & religion & religion \\
\hline 10 & hobby \& leisure & fishing, outdoor, travel, pet, ba-duk(go) \\
\hline 11 & drama \& entertainment & drama, sitcoms, variety, shows \\
\hline 12 & sports & sports \\
\hline 13 & movies & Movies \\
\hline 14 & cartoons & cartoons \\
\hline 15 & music & music shows, music videos \\
\hline 16 & games & game shows \\
\hline 17 & women & fashion, beauty \\
\hline 18 & foreign drama & Japanese/Chinese drama \\
\hline 19 & health & medical information \\
\hline 20 & lifestyle & cooking, weather, well-being, careers \\
\hline 21 & foreign satellite channel & channels offered by foreign program providers \\
\hline
\end{tabular}

As shown in table 3, comprehensive programming channels, which provide all kinds of programs, including news, entertainment, and sports programs, were highly ranked on a viewer rating list during this time period, while channels classified as drama or entertainment constituted 8 out of the top 20 list. Eight channels on the list are affiliated with terrestrial broadcasters, which usually retransmit affiliated terrestrial broadcaster's programs.

The monthly fee for a channel bundle is a variable to examine its correlation with household income. We used the regular price information of each channel bundle, except for DBS service, which only posts a discounted monthly fee for a 3-year contract 
Table 3. Viewers' Top 20 List from July 20 to August 9, 2014

\begin{tabular}{c|l|l|c}
\hline No. & \multicolumn{1}{|c|}{ Channel } & \multicolumn{1}{|c}{ Genre of channel } & Viewer Rating \\
\hline 1 & MBN & comprehensive programming channel & 0.5447 \\
\hline 2 & TV Chosun & comprehensive programming channel & 0.4730 \\
\hline 3 & Channel A & comprehensive programming channel & 0.4019 \\
\hline 4 & JTBC & comprehensive programming channel & 0.3238 \\
\hline 5 & YTN & news & 0.2680 \\
\hline 6 & MBC Drama Net & drama \& entertainment & 0.2455 \\
\hline 7 & TVN & drama \& entertainment & 0.2347 \\
\hline 8 & NewsY & news & 0.1963 \\
\hline 9 & KBS Drama & drama \& entertainment & 0.1643 \\
\hline 10 & SBS Plus & drama \& entertainment & 0.1501 \\
\hline 11 & MBC Sports & sports & 0.1407 \\
\hline 12 & Tooniverse & cartoons & 0.1310 \\
\hline 13 & KBS JOY & drama \& entertainment & 0.1290 \\
\hline 14 & OCN & movies & 0.1227 \\
\hline 15 & MBC Every1 & drama \& entertainment & 0.1148 \\
\hline 16 & Channel CGV & movies & 0.1063 \\
\hline 17 & Comedy TV & drama \& entertainment & 0.0972 \\
\hline 18 & SBS funE & drama \& entertainment & 0.0944 \\
\hline 19 & KBS N Sports & sports & 0.0783 \\
\hline 20 & Super Action & movies & \\
\hline & & & \\
\hline
\end{tabular}

on its homepage. So, for DBS service, we used this discounted price information. In addition, in order to calculate the total amount of monthly fee, we added the set-top box rental fee of $\$ 7,000$ to the basic charge of the digital cable TV, DBS, and IPTV services except for the analog cable TV service. Table 4 shows the summary statistics of the characteristics of the various channel bundle options.

As shown in table 4, analog cable tier 1 has the least genre diversity, and genre diversity increases from tier 1 to tier 3. IPTV shows more genre diversity than any other alternative, and yet the average viewer rating is the highest for analog cable tier 1 and the lowest for IPTV. The monthly fee is positively correlated with genre diversity but negatively correlated with the average viewer rating. The monthly fee for digital 
Table 4. Summary Statistics of Characteristics of Channel Bundle Options

\begin{tabular}{c|l|r|r|r|r}
\hline \multicolumn{2}{c|}{ Variable / Alternative } & \multicolumn{1}{c|}{ Min. } & \multicolumn{1}{c|}{ Max. } & \multicolumn{1}{c|}{ Mean } & \multicolumn{1}{c}{ S.D. } \\
\hline \multirow{4}{*}{$\begin{array}{c}\text { Genre diversity } \\
\text { (Simpson's Dz) }\end{array}$} & analog cable tier1 & 0.54 & 0.90 & 0.79 & 0.06 \\
\cline { 2 - 6 } & analog cable tier2 & 0.84 & 0.96 & 0.91 & 0.03 \\
\cline { 2 - 6 } & analog cable tier3 & 0.88 & 0.96 & 0.92 & 0.02 \\
\cline { 2 - 6 } & digital cable & 0.93 & 0.98 & 0.96 & 0.01 \\
\cline { 2 - 6 } & DBS & 0.96 & 0.97 & 0.97 & 0.00 \\
\cline { 2 - 6 } & IPTV & 0.97 & 0.98 & 0.98 & 0.00 \\
\hline \multirow{4}{*}{$\begin{array}{c}\text { Average Viewer } \\
\text { Rating }\end{array}$} & analog cable tier1 & 0.02 & 0.17 & 0.13 & 0.03 \\
\cline { 2 - 6 } & analog cable tier2 & 0.07 & 0.13 & 0.09 & 0.01 \\
\cline { 2 - 6 } & analog cable tier3 & 0.07 & 0.10 & 0.08 & 0.01 \\
\cline { 2 - 6 } & digital cable & 0.03 & 0.07 & 0.05 & 0.01 \\
\cline { 2 - 6 } & DBS & 0.04 & 0.04 & 0.04 & 0.00 \\
\cline { 2 - 6 } & IPTV & 0.03 & 0.07 & 0.04 & 0.01 \\
\hline \multirow{4}{*}{$\begin{array}{c}\text { Monthly fee } \\
\text { (W) }\end{array}$} & analog cable tier1 & 3,000 & 4,000 & $3,988.76$ & 106.00 \\
\cline { 2 - 6 } & analog cable tier2 & 5,000 & 10,000 & $7,993.22$ & 999.48 \\
\cline { 2 - 6 } & analog cable tier3 & 11,000 & 15,000 & 13,780 & $1,568.70$ \\
\cline { 2 - 6 } & digital cable & 16,000 & 33,000 & $24,232.00$ & $4,581.56$ \\
\cline { 2 - 6 } & DBS & 13,000 & 28,000 & $18,666.67$ & $8,144.53$ \\
\cline { 2 - 6 } & IPTV & 17,000 & 27,000 & $21,877.78$ & $3,407.26$ \\
\hline
\end{tabular}

cable turns out to be higher than for DBS and IPTV. But it is possible that there is a gap between our price data and the actual charges, as we have mentioned. ${ }^{6}$ Note that channel bundles in the same tier are not the same across the SOs. Hence we use the average values of the characteristics across the SOs in table 4 as the values of the characteristics of the alternatives in our estimation.

Variables of media use behavior include the amount of time spent watching terrestrial broadcasters' programs out of the total amount of time spent watching TV and the amount of time spent using VOD services, watching video contents via PCs or mobile devices, and surfing the internet. The data on the amount of time spent on each activity

6. In addition, some digital cable operators stopped selling the most expensive package of W26,000 without notifying customers on their homepages that they were no longer were selling it. 
Table 5. Summary Statistics of Media Use Behavior Variables

\begin{tabular}{l|c|c|c|c|c}
\hline \multicolumn{1}{c|}{ Variable } & min. & mid. & Max. & mean & S.D. \\
\hline $\begin{array}{l}\text { the share of time spent watching terrestrial } \\
\text { broadcasters' programs of the total amount of } \\
\text { time spent watching TV }\end{array}$ & 0 & 1 & 1 & 0.88 & 0.24 \\
\hline $\begin{array}{l}\text { the amount of time spent watching VOD via } \\
\text { TV (number of minutes over three days) }\end{array}$ & 0 & 0 & 1,620 & 12.13 & 66.76 \\
$\begin{array}{l}\text { the amount of time spent watching video via } \\
\begin{array}{l}\text { PCs or mobile devices (number of minutes } \\
\text { over three days) }\end{array}\end{array}$ & 0 & 0 & 1,035 & 9.89 & 44.70 \\
$\begin{array}{l}\text { the amount of time spent surfing the internet } \\
\text { (number of minutes over three days) }\end{array}$ & 0 & 82.5 & 2,805 & 132.18 & 169.86 \\
\hline
\end{tabular}

comes from the media usage diaries in the Korean Media Panel Survey. The survey respondents recorded what media they used, what they did with that media, and how they were connected to the media every 15 minutes for 3 days. We calculated the average usage of each variable by household and transformed it into a logarithmic scale. Table 5 shows the summary statistics of media use behavior.

The amount of time households spent watching terrestrial broadcasters' programs was approximately 0.88 on average. This number is consistent with the previous research, which suggests the polarization between the terrestrial channels and the other channels in Korea (Lee \& Kim, 2001; Park, 2009). The average amount of time households spent watching VOD via TV and watching videos via PCs or mobile devices turned out to be lower than that spent watching TV in real time, and it seems that there are heavy users of VOD services or video available online, considering skewed distributions of the two variables. This indicates that TV watching still plays a central role in most households' media consumption. Lastly, the summary statistics of internet surfing show that it has become relatively popular, but not as popular as TV watching.

Demographic variables in our data include householder's age, household type, residence location, average education, and household income. These demographics have been used as control variables in previous research (Bok, 2012; Goolsbee \& Petrin, 2004; Lee \& Kim, 2001; Park, 2009; Yoon et al., 2006; Wise \& Duwadi, 2005).

Householder age could be an important driver in determining whether a person purchases new digital devices or services and may also have a correlation with a preference for TV programs. So we use a dummy variable for whether the householder is under the age of 40 or not, considering that the age of 40 is commonly used as the separation point between youth and middle age in general. The household type could 
be another factor. The household that consists of only one person or married couple without children is expected to prefer the channel bundle with diverse channels and premium services. On the other hand, these households may not attach significance to the genre diversity of channel bundle given the composition of the household.

The area where the household is located is likewise expected to affect the kind of multichannel services the household subscribes to. IPTV service is delivered over a broadband network, and installation of such networks has been more concentrated in metropolitan cities than small cities or rural areas; DBS, on the other hand, is common in remote rural areas that do not have access to cable or broadband. Therefore, we use a dummy variable that indicates whether the household is located in a metropolitan city or not. In order to measure the average level of education among household members, we defined the household member's education level on a scale of zero to five, ${ }^{7}$ and then calculated the average value by household. Finally, household income seems to be correlated with the household's sensitivity to the price of channel bundle. Here we categorize the household that earns more than 1.5 times of the median household

Table 6. Summary Statistics of Demographic Variables

\begin{tabular}{|c|c|c|c|c|c|}
\hline & \multicolumn{3}{|c|}{ Variable } & Number & $\begin{array}{l}\text { Proportion } \\
(\%)\end{array}$ \\
\hline \multirow{2}{*}{ Age of Householder } & \multicolumn{3}{|l|}{ under 40} & 509 & 12.11 \\
\hline & \multicolumn{3}{|c|}{40 or above } & 3,694 & 87.89 \\
\hline \multirow{2}{*}{$\begin{array}{l}\text { Household Income } \\
\text { Level }\end{array}$} & \multicolumn{3}{|l|}{ upper level } & 697 & 16.58 \\
\hline & \multicolumn{3}{|c|}{ middle or lower level } & 3,506 & 83.42 \\
\hline \multirow[t]{2}{*}{ Household Type } & \multicolumn{3}{|c|}{$\begin{array}{l}\text { single dweller or married couple without } \\
\text { children }\end{array}$} & 1,545 & 36.76 \\
\hline & \multicolumn{3}{|c|}{ All the other household types } & 2,658 & 63.24 \\
\hline \multirow[b]{2}{*}{ Location of Residence } & \multicolumn{3}{|c|}{ household located in a metropolitan city } & 1,832 & 43.59 \\
\hline & \multicolumn{3}{|c|}{$\begin{array}{l}\text { Households located in small cities and } \\
\text { rural areas }\end{array}$} & 2,371 & 56.41 \\
\hline \multirow{2}{*}{ Average Education } & $\min$. & $\max$. & \multicolumn{2}{|c|}{ mean } & S.D. \\
\hline & 0 & 5 & \multicolumn{2}{|c|}{2.55} & 1.06 \\
\hline Observations & \multicolumn{5}{|c|}{4,203} \\
\hline
\end{tabular}

7. Preschooler/no schooling $=0$, elementary school graduate $=1$, middle school graduate $=2$, high school graduate $=3$, college graduate $=4$, graduate school graduate $=5$. 
income as an upper-income household. ${ }^{8}$ We include a dummy variable for upperincome households. Table 6 provides summary statistics of the demographic variables.

\section{RESULTS}

The results from estimating the mixed logit model in equations 1 and 2 are summarized in table 7. It turns out that households that preferred channel bundles composed of higher viewer-rating programs are those that spent more time watching terrestrial broadcaster's programs than other TV programs or who spent more time surfing the internet. Since lower- tier bundles have a smaller number of more popular TV programs, those households are more likely to choose the lower-tier bundles.

On the other hand, households that preferred channel bundles composed of a variety of genre are those who spent more time watching VOD on TV or who spent more time either watching videos via PCs/mobile devices or surfing the internet. One possible interpretation of these results is that users of VOD on TV or those who watch videos online are more likely to be exposed at a variety of genres and develop tastes for various media contents, which will lead them to place a higher value on the genre diversity of TV channel bundles. Hence, those households are more likely to subscribe to digital cable, DBS, or IPTV. ${ }^{9}$

Among demographic variables, household type and income level turned out to be relevant to the household's preferences with respect to channel bundle characteristics. Specifically, single dweller or married couples without children preferred channel bundles composed of more watched channels, while upper-income households were less sensitive to price, as expected. We may infer that social trends such as the rise in average age of first marriage, the decrease in the birth rate, and the increase in single dwellers in Korea would influence multichannel service consumption and the compo-

8. Equalized household income is calculated as follows:

$$
\text { equalized household income }=\frac{\text { household income }}{\sqrt{\frac{\text { the number of household members }}{\text { men }}}}
$$

9. Another interpretation is as follows. People who spend a lot time watching online videos via PC or smartphone usually subscribe to high-speed internet at home or a high-priced smartphone service with a larger data allowance. Digital cable SOs and IPTV providers typically offer discounts for bundled services that include multichannel TV service, a highspeed internet connection, and sometimes smartphone service. Therefore, households spending more time either watching videos via PCs or mobile devices or surfing the internet are more likely to subscribe to digital cable, DBS, or IPTV. 
Table 7. Estimation Results

\begin{tabular}{|c|c|c|c|}
\hline \multicolumn{2}{|r|}{ Interactions } & \multirow[b]{2}{*}{ Coefficient } & \multirow[b]{2}{*}{ S.E. } \\
\hline $\begin{array}{l}\text { Channel Bundle } \\
\text { Characteristics }\end{array}$ & Household Attributes & & \\
\hline \multirow{8}{*}{$\begin{array}{l}\text { Genre } \\
\text { Diversity }\end{array}$} & $\begin{array}{l}\text { the share of time spent watching terrestrial } \\
\text { broadcaster's programs out of all TV programs } \\
\text { available in real-time via TV }\end{array}$ & 51.2914 & 31.3676 \\
\hline & $\begin{array}{l}\text { the amount of time spent watching VOD via TV } \\
\text { (number of minutes over three days) }\end{array}$ & $34.3235^{*}$ & 18.1859 \\
\hline & $\begin{array}{l}\text { the amount of time spent watching video via } \\
\text { PCs or mobile devices (number of minutes } \\
\text { over three days) }\end{array}$ & $36.3945^{\star \star}$ & 17.6528 \\
\hline & $\begin{array}{l}\text { the amount of time spent surfing the internet } \\
\text { (number of minutes over three days) }\end{array}$ & $68.3160^{\star \star *}$ & 23.2462 \\
\hline & $\begin{array}{l}\text { household type (single dweller or married } \\
\text { couple without children) }\end{array}$ & 9.6279 & 13.2269 \\
\hline & age of householder (under 40 ) & 25.1132 & 22.6137 \\
\hline & residence located in a metropolitan city & 11.2610 & 12.7608 \\
\hline & average education & 17.6334 & 11.0661 \\
\hline \multirow{8}{*}{$\begin{array}{l}\text { Average } \\
\text { Viewer Rating }\end{array}$} & $\begin{array}{l}\text { the share of time spent watching terrestrial } \\
\text { broadcaster's programs out of all TV programs } \\
\text { available in real-time via TV }\end{array}$ & $66.4311^{\star \star}$ & 28.8907 \\
\hline & $\begin{array}{l}\text { the amount of time spent watching VOD via TV } \\
\text { (number of minutes over three days) }\end{array}$ & -7.5158 & 10.3383 \\
\hline & $\begin{array}{l}\text { the amount of time spent watching video via } \\
\text { PCs or mobile devices (number of minutes } \\
\text { over three days) }\end{array}$ & 12.1196 & 10.1176 \\
\hline & $\begin{array}{l}\text { the amount of time spent surfing the internet } \\
\text { (number of minutes over three days) }\end{array}$ & $46.2254^{\star * *}$ & 15.6611 \\
\hline & $\begin{array}{l}\text { household type (single dweller or married } \\
\text { couple without children) }\end{array}$ & $26.4943^{\star \star}$ & 12.3782 \\
\hline & age of householder (under 40) & -2.1223 & 14.7885 \\
\hline & residence located in a metropolitan city & -1.8760 & 8.4336 \\
\hline & average education & -9.6362 & 7.2434 \\
\hline Monthly Fee & upper-income household & $0.0001^{\star *}$ & 0.0000 \\
\hline \multirow{6}{*}{$\begin{array}{l}\text { Mean Utility } \\
\text { Level }\end{array}$} & analog cable tier 1 & $-37.51^{* *}$ & 17.82 \\
\hline & analog cable tier 2 & -24.05 & 14.89 \\
\hline & analog cable tier 3 & $-48.24^{\star \star}$ & 22.59 \\
\hline & digital cable TV & $-25.79^{\star}$ & 15.09 \\
\hline & DBS & $-82.33^{\star}$ & 46.11 \\
\hline & IPTV & $-30.29^{*}$ & 16.26 \\
\hline
\end{tabular}

log likelihood: $-5,666$

Observations: 4,203

${ }^{* * *} \mathrm{p}<.01,{ }^{* *} \mathrm{p}<.05,{ }^{*} \mathrm{p}<.1$ 
sition of its channel bundles.

The coefficients associated with the other demographic variables are not statistically significant. However, the signs of coefficients suggest that households with a higher average level of education might value genre diversity, but are not interested in popular channels. Although this result is not supported at a statistically significant level, it might imply that households with higher education prefer digital cable, DBS, or IPTV in Korea. This implication is not accordance with Goolsbee \& Petrin's (2004) result, which suggests that the average level of household education is positively associated with the utility increase of antenna only (relative to multichannel services).

\section{CONCLUSION}

In this paper, we have analyzed whether and how consumers' preferences with respect to channel bundles offered by multichannel services is affected by their media use behaviors. The results show that some media use behaviors lead consumers to prefer certain channel bundle characteristics such as genre diversity and average viewer rating. Specifically, households that tend to watch terrestrial TV programs in real time or that spend more time surfing the internet obtain higher utility from channel bundles composed of most watched channels. Households spending more time using VOD services via TV, watching online videos via PCs or mobile devices, or surfing the internet have a preference for channel bundles with more genre diversity. We also find that the income level and the household type are associated with the choice of multichannel services.

Watching terrestrial TV programs has been a great part of daily media consumption for many decades. However, the amount of time spent using VOD services or watching online videos via PCs or mobile devices is expected to grow exponentially as digital convergence proceeds. Given the results of this paper, as the demand for diverse genres increases, multichannel service providers would pay more attention to meeting this demand by supplying more customized channel bundles or exclusive VOD content. Moreover, considering that leading companies of over-the top services such as Netflix have entered the Korean market, multichannel service providers' competition for content variety, especially between digital cable and IPTV, will grow. However, the law applied to IPTV service is different from the one applied to the other multichannel services, and this asymmetric regulation could hinder fair competition between IPTV service providers and the other ones. Therefore, an integrated broadcasting act is necessary to promote competitiveness and encourage efficiency in the media industry.

Although we could not fully control the effect of bundled discounts or long-term 
contracts due to the lack of the relevant data, this paper contributes to the existing literature as a first step to quantitatively analyze the way in which and the extent to which changes in consumer's media use behavior affect multichannel service providers' strategies and related industry. With more data over a longer period of time, we will be able to obtain more exquisite results on the interaction between consumers' media use behavior and the evolution of the media industry.

\section{REFERENCES}

Bok, H. 2012. Analysis on the diversion ratio among multichannel video services using the mixed logit model. Korean Journal of Industrial Organization, 20(1): 116-150.

Cho, S., \& Kang, N. 2008. Audience concentration and polarization in a multichannel environment. Korean Journal of Journalism and Communication Studies, 52(4): $152-178$.

Ferguson, D. A., \& Perse, E. M. 2000. The World Wide Web as a functional alternative to television. Journal of Broadcasting \& Electronic Media, 44(2): 155-174.

Goolsbee, A., \& Petrin, A. 2004. The consumer gains from direct broadcast satellites and the competition with cable TV. Econometrica, 72(2): 351-381.

Han, H. 2012. An exploratory study on paradigms; policies in the digital convergence era. Journal of Digital Convergence, 10(1): 455-461.

Han, Y., \& Lee, S. 2012. Relationship between N-screen service and home TV; focusing on the Korean representative N-screen service, Tving. Journal of the Korea Content Association, 12(5): 144-153.

Hong, J., \& Lee, S. 2009. A study of the influence of competition in cable TV market on diversity; focusing on comparison of diversity between monopoly and duopoly areas. Journal of Communication Research, 46(2): 101-126.

Hwang, Y. 2004. Research on the relationship between TV viewing and internet using in the context of time and space. Korean Journal of Broadcasting \& Telecommunications Research, 59: 309-338.

James, M. L., Wotring, C. E., \& Forrest, E. J. 1995. An exploratory study of the perceived benefits of electronic bulletin board use and their impact on the other communication activities. Journal of Broadcasting \& Electronic Media, 39(1): 30-50.

Kang, M. 2000. Exploring the relationship between the traditional media use and the internet use. Korean Journal of Broadcasting \& Telecommunications Research, 50: $179-208$.

Kaye, B. K., \& Johnson, T. J. 2003. From here to obscurity? Media substitution theory 
and traditional media in an on-line world. Journal of American Society for Information Science and Technology, 54(3): 260-273.

Korea Communications Commission. 2009-2013. Broadcasting industry survey, 20092013. Gyeonggi-do: Korea Communications Commission.

KCTA. 2014. Status of cable TV subscribers, July 2014. Retrieved on September 1, 2014, from http://www.kcta.or.kr.

Kim, H., Kim, J., \& Jeong, S. 2013. Effect of smartphone use on traditional media uses: Application of media substitution hypothesis. Journal of Media Economics \& Culture, 11(1): 88-119.

Korean Information Society Development Institute. 2013. Korean Media Panel Survey 2013. Retrieved on July 2, 2014, from http://stat.kisdi.re.kr/Library.

Lee, G. 2009. Quantitative analyses of the effects of internet use on TV viewing. Journal of Cyber communication Academic Society, 26(3): 128-158.

Lee, J., \& Na, E. 2012. The influence of motivation for using smartphone applications and innovativeness compatibility on its application use and substitution for other media living equipment. Korean Journal of Journalism \& Communication Studies, 56(5): 5-35.

Lee, S., \& Kim, K. 2001. A study on channel repertoire in cable television with regard to viewing diversity and polarization of audiences. Korean Journal of Journalism \& Communication Studies, 45(3): 268-297.

Lee, S., \& Lee, S. 2013. Time displacement effect of online video service on pay TV. Korean Telecommunications Policy Review, 20(4): 73-103.

Lim, J., Yoon, J., \& Jo, E. 2013. Uses of media across dayparts according to gender, age and weekdays/weekend. Social Science Research Institute, 21(2): 144-168.

McDonald, D. G., \& Dimmick, J. 2003. The conceptualization and measurement of diversity. Communication Research, 30(1): 60-79.

Park, M., \& Lee, S. 2010. Consumers' valuation of the attributes of pay TV: An empirical evaluation. Korean Journal of Journalism \& Communication Studies, 54(4): 189-208.

Park, M., \& Jung, J. 2010. An empirical study on the subscription to internet protocol television services in Korea. Korean Telecommunications Policy Review, 17(2): 55-78.

Park, S. 2010. Identification and estimation of multinomial choice models. Korean Journal of Industrial Organization, 18(3).

Park, Y. 2009. An empirical analysis of content consumption in a multimedia environment. KISDI Research Report 09-08. Gyeonggi-do: Korea Information Society Development Institute.

Yoon, C., Lee, I. \& Lee, D. 2006. An empirical study of the competition between 
cable television and direct broadcast satellite. Korean Telecommunications Policy Review, 13(4): 159-182.

Yu, S. 2004. The interrelationship between television and internet use. Korean Journal of Broadcasting and Telecommunication Studies, 13(8): 475-520.

Wise, A., \& Duwadi, K. 2005. Competition between cable television and direct broadcast satellite: The importance of switching costs and regional sports networks. Journal of Competition Law \& Economics, 1(4): 679-705. 